\title{
Imaging of cervical spine involvement in inflammatory arthropathies: a review
}

\author{
Mateusz Kotecki ${ }^{1, A, B, D, E, E, F}$, Maria Sotniczuk ${ }^{1, D, E}$, Piotr Gietka ${ }^{2, A, D, E}$, Robert Gasik ${ }^{3, A, D, E}$, Iwona Sudoł-Szopińska ${ }^{1, A, D, D, E}, F$ \\ 'Department of Radiology, National Institute of Geriatrics, Rheumatology and Rehabilitation, Warsaw, Poland \\ ${ }^{2}$ Department of Paediatric Rheumatology, National Institute of Geriatrics, Rheumatology, and Rehabilitation, Warsaw, Poland \\ ${ }^{3}$ Department of Neuro-orthopaedics and Neurology, National Institute of Geriatrics, Rheumatology, and Rehabilitation, Warsaw, Poland
}

\begin{abstract}
The cervical spine can be affected by many types of inflammatory arthropathies, and the most common autoimmune diseases with cervical spine involvement are rheumatoid arthritis (RA), spondyloarthritis (SpA), and juvenile idiopathic arthritis (JIA). The clinical symptoms of cervical spine pathologies are often nonspecific or absent; therefore, imaging plays a crucial diagnostic role. RA is the most prevalent autoimmune disease; it often leads to cervical spine instability and subsequent myelopathy. In SpA, due to new bone formation, the characteristic lesions include syndesmophytes, parasyndesmophytes, and bone ankylosis, but instabilities are rare. In JIA, early apophyseal bone ankylosis is characteristic, in addition to impaired spinal growth. The aim of this review article is to discuss the imaging pathologies found in patients with RA, SpA, and JIA in the early and advanced stages. This knowledge would be helpful in the proper diagnosis and treatment of these diseases.
\end{abstract}

Key words: cervical spine, rheumatoid arthritis, spondyloarthritis, ankylosing spondylitis, psoriatic arthritis, juvenile idiopathic arthritis.

\section{Clinical presentation}

The cervical (C) spine is frequently involved in many inflammatory arthropathies. The most common are autoimmune disorders from the first 2 groups of rheumatic diseases, which are connective tissue diseases (such as rheumatoid arthritis [RA] and juvenile idiopathic arthritis [JIA]) and spondyloarthritis (SpA), among which the C-spine is mainly affected by psoriatic arthritis [1].

RA is the most common type of inflammatory arthritis. The C-spine, after the hands and wrists and the feet, is the third most commonly affected anatomical area in $86 \%$ of patients. The $\mathrm{C} 1-\mathrm{C} 2$ joint is most frequently involved. In approximately $20-70 \%$ of patients, C-spine lesions develop 10-11 years after disease onset, but in some individuals they may occur early and lead to instability.
This condition, if untreated, may cause myelopathy with neurological deficits [2].

In RA, damage is caused by synovial and bone marrow inflammation (osteitis) [3,4]. As the disease progresses, pannus may lead to ligamental laxity and tears with subsequent atlanto-axial subluxation in different directions. Moreover, bone marrow inflammation and synovitis may lead to cartilage and bone damage with subchondral cysts and erosion [4]. Massive erosions with complete ligamental destruction may cause posterior or vertical atlantoaxial subluxations with subsequent spinal cord myelopathy or brain stem compression, which are life-threating conditions [5]. In addition to the $\mathrm{C} 1 / \mathrm{C} 2$ level, subaxial spinal involvement may include (pseudo)spondylolisthesis, spinous process erosions, and rarely, discitis. Regardless of the disease duration, some patients may develop

Correspondence address:

Mateusz Kotecki, Department of Radiology, National Institute of Geriatrics, Rheumatology, and Rehabilitation, 1 Spartanska St., 02-637 Warsaw, Poland, e-mail: mateuszjankotecki@gmail.com

Authors' contribution:

A Study design · B Data collection · C Statistical analysis · D Data interpretation · E Manuscript preparation · F Literature search · G Funds collection 
apophyseal joint ankylosis, which is also a risk factor for spinal myelopathy and cervical radiculopathy [6].

$\mathrm{SpA}$ does not frequently involve the $\mathrm{C}$-spine. This group includes seronegative diseases (negative rheumatoid factor), such as ankylosing spondylitis (AS), psoriatic arthritis (PsA), reactive arthritis ( $\operatorname{ReA})$, arthritis associated with inflammatory bowel disease (IBD-related arthritis), and undifferentiated SpA [7]. Human leukocyte antigen (HLA)-B27 antigen positivity is associated with a higher prevalence of $\mathrm{SpA}$, and the risk of developing $\mathrm{SpA}$ in the presence of HLA-B27 antigen positivity is 20 times greater than in the general population [8]. AS involves the $\mathrm{C}$-spine in advanced disease, while PsA tends to involve the $\mathrm{C}$-spine early in the disease. The lesions are SpA-specific and include syndesmophytes, parasyndesmophytes, ankylosis, vertebral squaring, and ligamental calcifications. They may less frequently show RA features, such as $\mathrm{C} 1 / \mathrm{C} 2$ involvement with subluxations or dens erosions, which are mainly seen in PsA [9].

Enthesitis plays a crucial role in the pathogenesis of SpA-related lesions, and in the spine, it is observed in the anulus fibrosus of intravertebral joints. Early changes include bone marrow oedema (BME) of the anterior vertebral edges, also referred to as corner inflammatory lesions (CIL), with subsequent erosions (Romanus lesions) and triangular sclerosis, which are also called shiny corners. In more advanced disease, vertebral squaring (i.e. remodelling of the anterior aspect of the vertebral body) may be seen. This lesion is presumed to be caused by chronic osteitis and repair [10]. Syndesmophytes are the anterior or lateral ossification of anulus fibrosus or ligamental structures. In advanced disease, they may lead to ankylosis and spinal immobility.

Ankylosis affects longitudinal, flavum, interspinous, and supraspinous ligaments. In advanced disease, ligamental calcification may be encountered, typically in the posterior longitudinal ligament [11]. BME and the fatty degeneration of vertebral corners visible on magnetic resonance imaging (MRI) may predict the formation of new syndesmophytes $[12,13]$. Additionally, spinal fractures mainly occur in advanced AS and are often caused by minor trauma. At the cervical level, spinal fractures may lead to spinal cord injury or even sudden death [14]. Parasyndesmophytes are thick and irregular asymmetric syndesmophytes that sometimes occur in PsA and are less frequently observed in ReA [9].

JIA is the most common inflammatory arthritis of autoimmune and autoinflammatory origin in children under the age of 16 years. It is divided into 7 subtypes: oligoarticular JIA, seropositive polyarticular JIA, seronegative polyarticular JIA, systemic-onset JIA (sJIA), enthesitis-related arthritis (ERA), juvenile psoriatic arthritis (JPsA), and undifferentiated JIA [15]. JIA is characterized primarily by peripheral joint arthritis, but the $\mathrm{C}$-spine can be affected in up to $80 \%$ of patients, most commonly in those with a polyarticular course of JIA [16].
C-spine lesions include synovial inflammation with pannus formation and BME. The indolent process of leucocyte infiltration into the synovium and proliferation of the synovial tissue lead to a subacute type of inflammation, which may explain why pain is not the most conspicuous feature of the clinical presentation of JIA and is sometimes absent, particularly in oligoarthritis JIA [17]. The most striking features of JIA are early C-spine apophyseal joint ankylosis accompanied by bone growth developmental disturbances, such as vertebral or disc hypoplasia caused by chronic inflammation and long-term steroid use [18]. Erosions and subluxations, similar to those observed in RA, also occur [16,19].

The first-line imaging modality for RA, SpA, and JIA is radiography, both static and dynamic. However, MRI allows for a more precise diagnosis of $\mathrm{C}$-spine lesions, especially in terms of early diagnosis and when there is brainstem, spinal cord, or nerve-root involvement [20]. Computed tomography (CT) is mainly used preoperatively. The aim of this article is to review imaging features in $\mathrm{RA}, \mathrm{SpA}$, and JIA, taking into consideration the different pathogenetic backgrounds of each of them.

\section{Imaging techniques}

\section{Radiography}

Classic radiography is relatively effective in the assessment of bone lesions and C-spine alignment. The most commonly used views include lateral and anteroposterior (AP) projections, with the latter used for alignment and Luschka joint assessment. In rheumatological settings, functional lateral projections are often requested by clinicians or neuro-orthopaedic surgeons (flexion, extension, and neutral views) to assess subluxations, especially at the $\mathrm{C} 1-\mathrm{C} 2$ level. The lack of functional views and reliance only on lateral neutral projection leads to failed diagnosis in almost $50 \%$ of cases [21].

Another view used in rheumatology is AP projection with an open mouth, which is used to assess C1-C2 alignment and dens (Figure 1). However, in current practice,

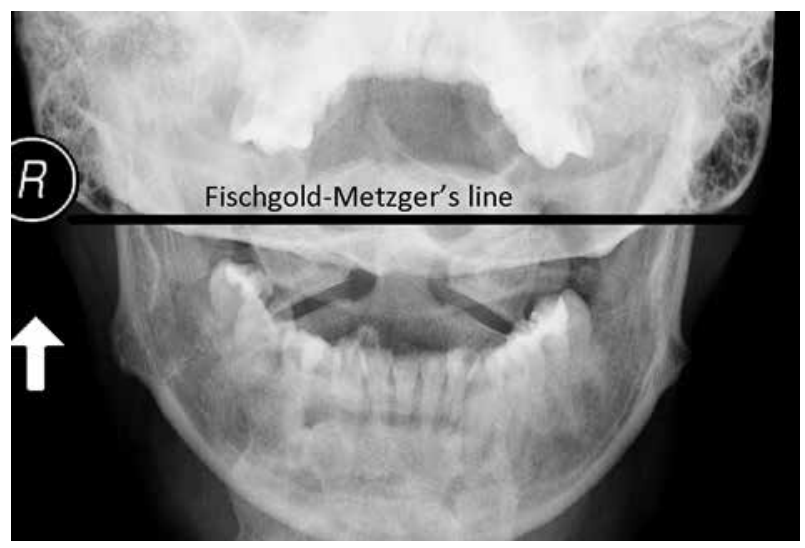

Figure 1. AP open mouth projection: Fischgold-Metzger's line - example of measuring vertical subluxation 
this view is rarely performed because it has been replaced by MRI and CT, which allow for a precise evaluation of this complex anatomical area. The significant limitation of plain radiography of the craniocervical junction is the superimposition of anatomical structures, which is especially common when rotational instability is present.

The evaluation of soft tissue in classical radiography is limited. However, in cases involving trauma, prevertebral soft tissue thickening can be assessed. The cut-offs for prevertebral thickness are $7 \mathrm{~mm}$ and $21 \mathrm{~mm}$ at the $\mathrm{C} 2 / \mathrm{C} 3$ and C6/C7 levels, respectively [22]. In some patients, nonfused ossification centres are seen (e.g. os odontoideum), which need to be differentiated from fractures. In children, due to the laxity of the spine, false results concerning spondylolisthesis need to be considered.

\section{Magnetic resonance imaging}

Typical MRI protocols include sagittal T1- and T2-weighted sequences, T2 STIR (short tau inversion recovery), and axial T2-weighted images. Optionally, the coronal T2-weighted sequence can be used, primarily to evaluate lateral subluxation. Furthermore, sagittal post-contrast T1-weighted images can be used to assess active inflammatory lesions, mainly synovitis [23]. MRI is considered the gold standard for spinal cord and nerve-root imaging. Fluid-sensitive sequences with fat saturation are preferred for visualizing bone marrow oedema. MRI shows cysts, erosions of the dens or spinous processes, or vertebral endplates and spinal cord involvement in the C-spine.

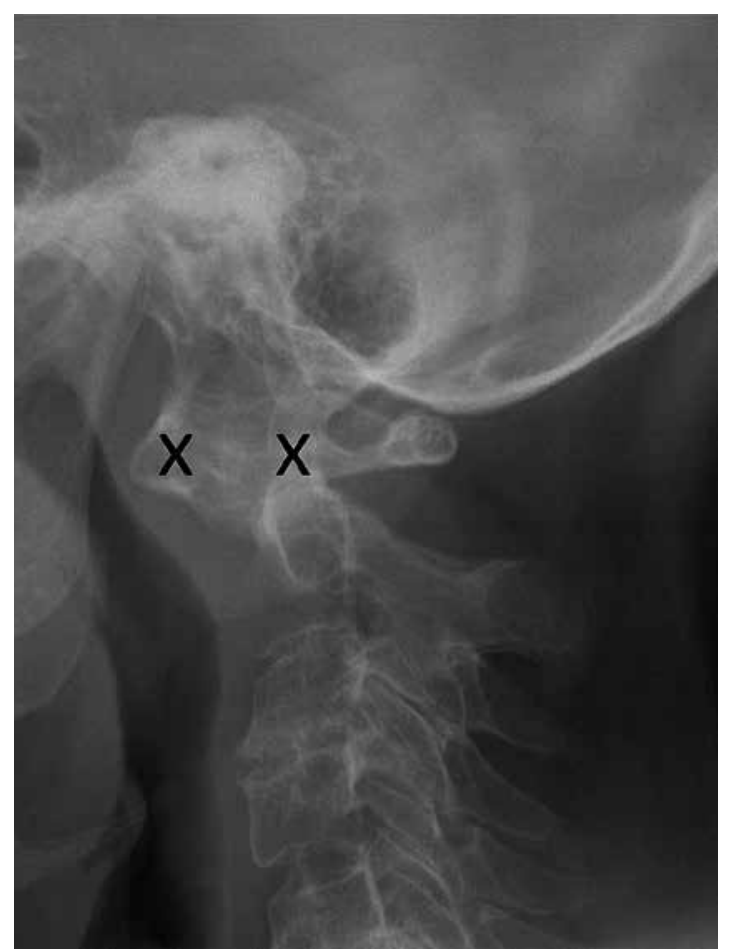

Figure 2. Lateral radiograph of 59 y.0. female diagnosed with RA showing anterior AAS $-14 \mathrm{~mm}$ and dens erosions (between crosses). Bone loss and secondary osteoarthritis is also seen
Functional MRI of the C-spine that includes flexion, extension, and neutral positions is possible, but it is not used in routine practice [24].

\section{Computed tomography}

For neuro-orthopaedic surgeons, CT of the C-spine is requested in almost all cases before surgery. With the possibility of 3-dimensional (3-D) reconstruction, CT perfectly outlines the complex anatomy of the cranio-cervical junction, including the atlanto-occipital joint, atlantoaxial joint, intervertebral joints, uncovertebral (Luschka) joints, and apophyseal joints. Multiplanar CT is superb in the visualization of anatomical variants, cysts, erosions, dens fractures, and subluxations, including the most challenging for radiography, the atlanto-axial level, as well as ankylosis. Although CT is superior in the assessment of soft tissue involvement when compared to radiography, it is still inferior to MRI, especially in the context of spinal cord and nerve-root imaging.

\section{Imaging features of cervical spine pathologies}

\section{Subluxation}

Rheumatological diseases, including RA, SpA, and JIA, have several disease-specific imaging features and share some common imaging features, including axial and subaxial subluxations and related spinal canal stenosis. This major cervical pathology, which is characterized by inappropriate vertebral alignment, can be divided into 2 categories based on the level of spine involvement: atlantoaxial at the $\mathrm{C} 1-\mathrm{C} 2$ level and subaxial at the $\mathrm{C} 2-\mathrm{C} 7$ level.

Atlanto-axial subluxation (AAS) is defined as a pathological alignment between the atlas (C1) and the dens of the axis (C2). It may occur in 3 dimensions: horizontal (anterior and posterior), lateral (right or left), and vertical (superior only). In anterior AAS, the distance between the posterior aspect of C1's anterior arch and the anterior part of the dens (i.e. the anterior atlanto-dental interval [AADI]) exceeds $3 \mathrm{~mm}$ in adults (Figure 2) and $5 \mathrm{~mm}$ in children. Skeletal immaturity allows greater joint laxity in children, and the presence of cartilage causes a larger AADI. Posterior AAS is usually caused by a fracture or erosion of the dens (Figure 3 ). It strongly suggests spinal cord compression and is a predictor of neurological deficits [5]. In posterior AAS, when the distance between the posterior part of the dens and the anterior aspect of the posterior $\mathrm{C} 1$ arch (i.e. the posterior atlanto-dental interval [PADI]) is less than $14 \mathrm{~mm}$, an urgent neurosurgical consultation is indicated. Lateral AAS is characterized by a displacement or asymmetry of $\mathrm{C} 2$ in relation to $\mathrm{C} 1$ that is equal to or greater than $2 \mathrm{~mm}$. An open-mouth AP radiograph may be used to assess this pathology, but currently CT is more commonly performed to confirm the diagnosis [20]. 

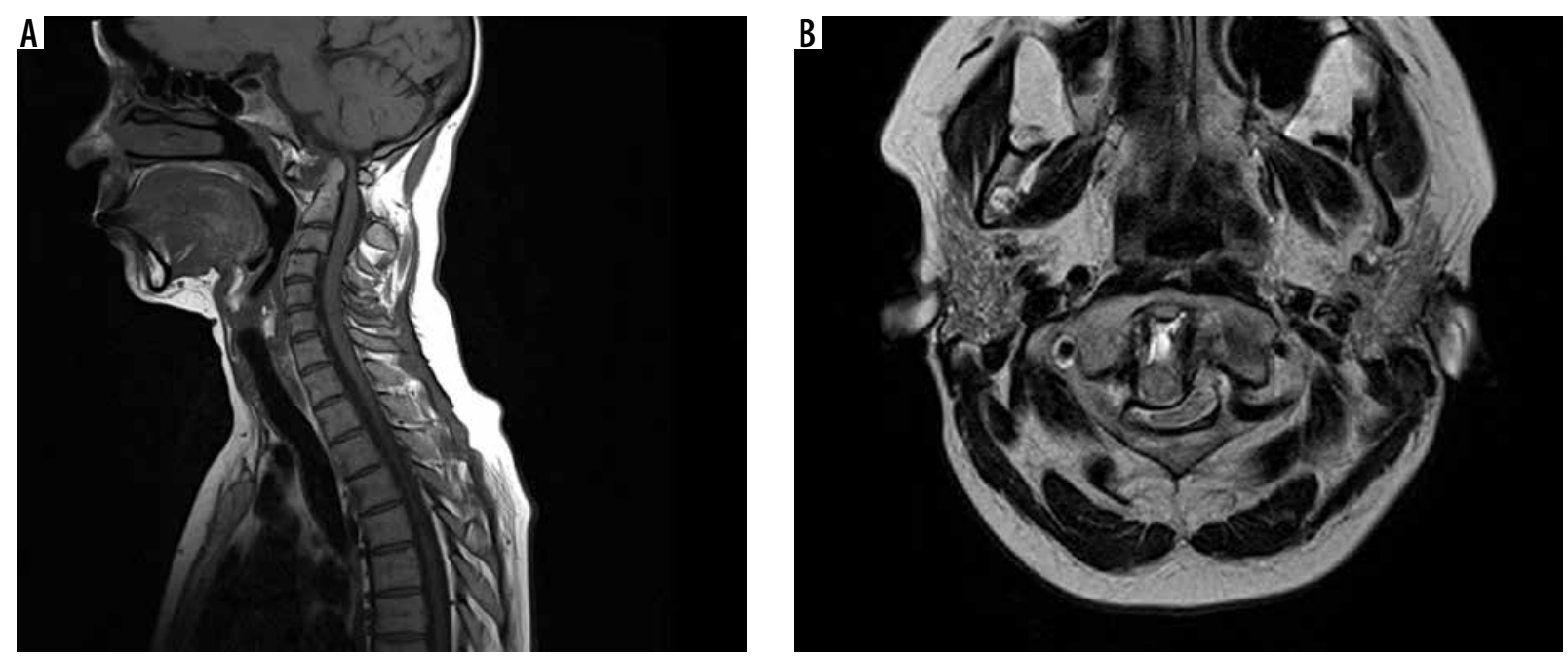

Figure 3. MRI of 44 y.o. female diagnosed with RA. A) T1-weighted sagittal scan showing anterior and posterior subluxation. Posterior atlanto-dental interval (PADI) is $6.5 \mathrm{~mm}$. B) T2-weighted axial scan showing lateral and posterior subluxation with spinal cord compression by dens inflammatory tissue fills the space of $\mathrm{C} 1 / 2$ anteriorly to dens

Vertical AAS, also referred to as basilar settling, basilar invagination, or cranial settling, is defined as a vertical migration of the dens into the foramen magnum. It is usually caused by massive ligamental destruction or erosion at the occipito-atlanto-axial level. Basilar settling is almost always preceded by anterior AAS. Several methods are used to assess vertical AAS (Table 1; Figures 1 and 4-8). No method is ideal; however, if results obtained using Ranawat's method, Redlunde Johnell's line, or Clark's method (or any combination thereof) are positive, the presence of vertical AAS is strongly suggested [25]. Approximately $6 \%$ of patients are misdiagnosed using these measurements in radiography. Therefore, a CT or an MRI should be performed when basi- lar settling is strongly suspected. It is worth mentioning that a phenomenon called pseudostabilization may occur with the presence and progression of basilar settling. In this case, the anterior AAS may decrease, and the dens seems to be stabilized on the anterior arch of the $\mathrm{C} 1$ axis [26]. Subaxial subluxation (SAS) is caused by progressive damage to the intervertebral, uncovertebral, and facet joints. The criterion for SAS is a greater than $3.5 \mathrm{~mm}$ displacement of adjacent vertebrae [27]. Other authors have suggested cut-off values of $2 \mathrm{~mm}$ and $4 \mathrm{~mm}$ for severe instability (Figure 9) [28].

Cervical canal stenosis is diagnosed when the AP diameter of the spinal canal is below $10 \mathrm{~mm}$ (absolute stenosis). Relative stenosis is diagnosed when the AP diameter is 10-13 mm [29].

Table 1. Comparison of different methods assessing basilar setting

\begin{tabular}{|c|c|c|}
\hline Method name & Description & Criterion for basilar setting \\
\hline McGregor's line [36] & $\begin{array}{l}\text { Line between posterior aspect of hard palate and lowest part } \\
\text { of occipital bone }\end{array}$ & Apex of dens is $4.5 \mathrm{~mm}$ above the line \\
\hline Chamberlain's line [37] & Line between posterior aspect of hard palate and opisthion & Apex of dens is $3 \mathrm{~mm}$ above the line \\
\hline McRae's line [38] & Line between basion and opisthion (foramen magnum) & Apex of dens is above the line \\
\hline Wackenheim's line [39] & Line drawn along the superior surface of clivus & Dens is located posterior to the line \\
\hline $\begin{array}{l}\text { Fischgold-Metzger's } \\
\text { line [40] }\end{array}$ & Line between mastoid processes on AP open mouth view & Apex of dens is above the line \\
\hline $\begin{array}{l}\text { Kauppi-Sakaguchi's } \\
\text { method [41] }\end{array}$ & $\begin{array}{l}\text { Three lines are drawn: Upper line between superior edges } \\
\text { of anterior and posterior } \mathrm{C} 1 \text { arch, lower line between inferior } \\
\text { margins of anterior and posterior arch of } \mathrm{C} 1 \text {, and middle line } \\
\text { which connects midpoints of both arches. The superior facets } \\
\text { of C2 (SFC2) are assessed. }\end{array}$ & $\begin{array}{l}\text { Grade I: normal, SFC2 don't cross lower line } \\
\text { Grade II: abnormal, SFC2 lie between lower and middle lines } \\
\text { Grade III: abnormal, SFC2 lie between middle and superior } \\
\text { lines } \\
\text { Grade IV: abnormal, SFC2 cross upper line }\end{array}$ \\
\hline Ranawat's method [42] & $\begin{array}{l}\text { Line between central part of } \mathrm{C} 2 \text { pedicle and intersection } \\
\text { of horizontal line drawn along the axis }\end{array}$ & Length below $<15 \mathrm{~mm}$ in males, $<13 \mathrm{~mm}$ in females \\
\hline Redlund Johnell's line [43] & $\begin{array}{l}\text { Line between McGregor's line and midpoint of caudal edge } \\
\text { of }(2 \text { body }\end{array}$ & Length below $<34 \mathrm{~mm}$ in males, $<29 \mathrm{~mm}$ in females \\
\hline Clark's method [44] & $\begin{array}{l}\text { Dens is divided into } 3 \text { equal stations on sagittal projection } \\
\text { from superior to inferior }\end{array}$ & Anterior arch of $\mathrm{C} 1$ is adjacent to II or III station \\
\hline
\end{tabular}




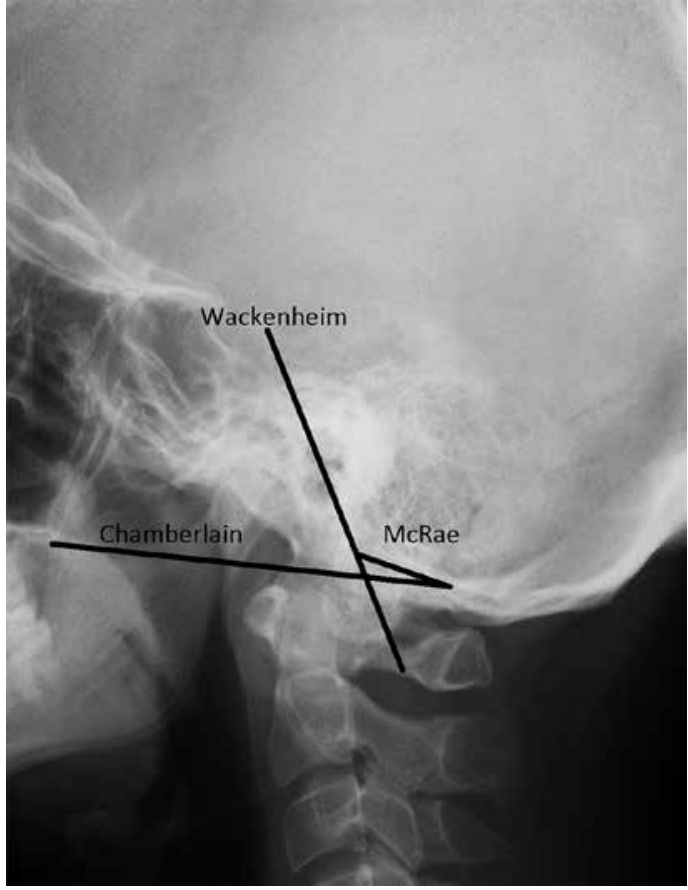

Figure 4. Lateral radiograph of healthy subject showing Chamberlain's, McRae's, and Wackenheim's lines

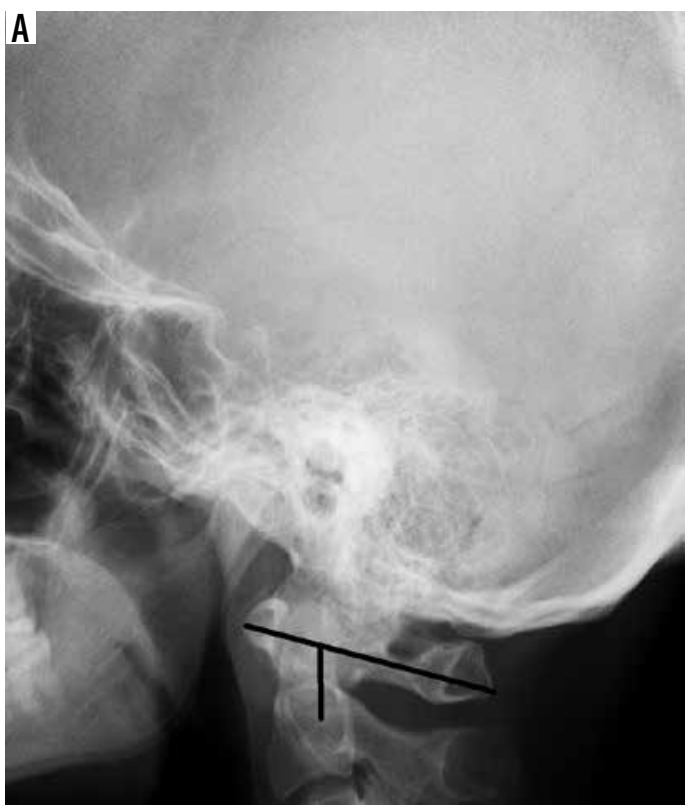

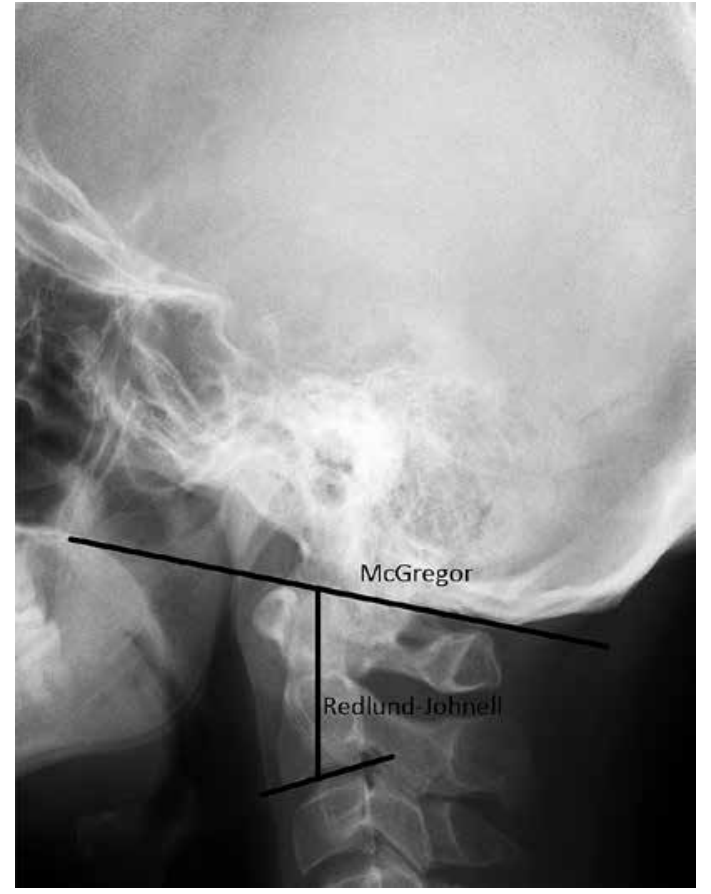

Figure 5. Lateral radiograph of healthy subject showing McGregor's and Redlund-Johnell's lines

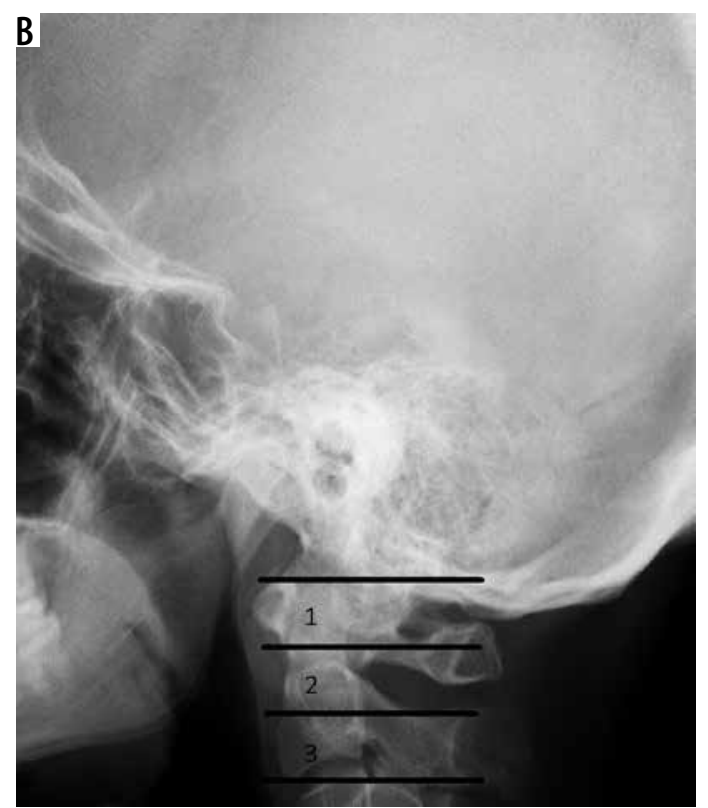

Figure 6. Lateral radiograph of healthy subject showing Ranawat's line (A) and Clark's method (B)

The preferred plane of measurement is lateral projection. The cervico-medullary angle (CMA) is the angle between lines drawn parallel to the anterior border of the upper cervical cord and the medulla oblongata. Normal values range between $135^{\circ}$ and $175^{\circ}$ [30], and values lower than $135^{\circ}$ indicate the need for surgery when other clinical symptoms are present.

\section{Rheumatoid arthritis}

Imaging findings in RA include demineralization, bone marrow oedema, cysts, erosions, inflammatory pannus, subluxations, spondylolyses, ankylosis, and compres- sion of the spinal cord, brain stem, or nerves. Younes et al. reported finding $\mathrm{C} 1 / \mathrm{C} 2$ pannus formations in $62.5 \%$ of patients and dens erosions in $67.5 \%$ of patients with diagnosed RA and a disease duration of 2 or more years. Pannus leads to erosions and multidirectional subluxations, followed by ligament damage. Ligament lesions at the $\mathrm{C} 1 / 2$ are seen in approximately $65 \%$ of patients, and anterior AAS is the most common subluxation. Lateral AAS occurs in up to $20 \%$ of patients, while posterior AAS is observed in approximately $7 \%$. Basilar settling (vertical AAS) and SAS occur in $20 \%$ and $15 \%$ of patients, respectively [31]. Posterior AAS is the most severe and 


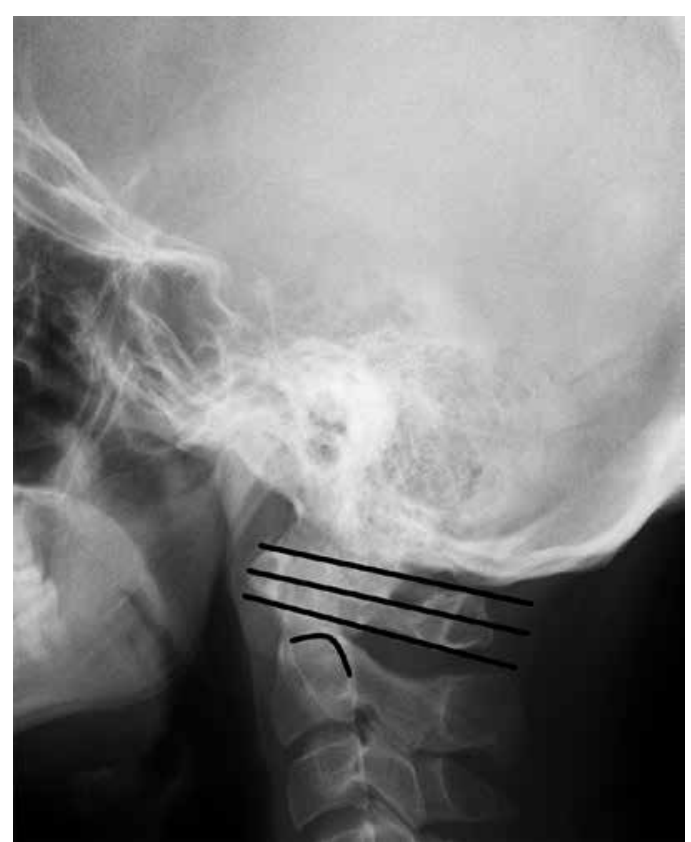

Figure 7. Lateral radiograph of healthy subject showing Kauppi-Sakaguchi method (curved line - superior facets of $(2)$

life-threatening type of subluxation and results from severe dens destruction, along with ligamental damage. Dens erosions and cysts can be visualized by radiography, CT, and MRI, while MRI or CT is used for inflammatory pannus, and MRI is used for bone marrow oedema (Figures 10-12) [20].

Cervical myelopathy can be caused by mechanical compression, vascular ischaemia, or both in a subluxated spine [32]. Patients with atlas erosion and a reduced distance between the dens and McRae's line have a 5-fold increased risk of neurological manifestations [33]. In a previous study, occipital pain was present in all patients with basilar settling, while $80 \%$ had myelopathy, $53 \%$ had a history of loss of consciousness, $38 \%$ had signs of brainstem dysfunction, and $22 \%$ had lower cranial nerve palsies [34]. Therefore, it should be stressed that the severity of spinal cord compression is often underestimated in clinical exams. In a study conducted by Bundschuh et al., all patients with a cervicomedullary angle below $135^{\circ}$ had either brain steam compression, myelopathy, or $\mathrm{C} 2$ nerve-root pain (Figure 13) [30].

The following measurements are important criteria for spinal surgery: AADI $>6 \mathrm{~mm}$, PADI $<14 \mathrm{~mm}$, absolute cervical canal stenosis $\leq 10 \mathrm{~mm}, \mathrm{CME}<135^{\circ}$, and the presence of neurological symptoms (e.g. pain). Consensus has not been reached on whether surgery should be performed on patients with instability without clinical symptoms, which occurs in up to $15-50 \%$ of patients with RA [35]. In a retrospective study performed by Collins et al. [36], $50 \%$ of patients suffering from RA with no clinical signs had radiographic findings of cervical instability. In the symptomatic group, the most common manifestation was pain localized in the neck or the occipital, retro-orbital, or temporal regions [36]. Another study found that the

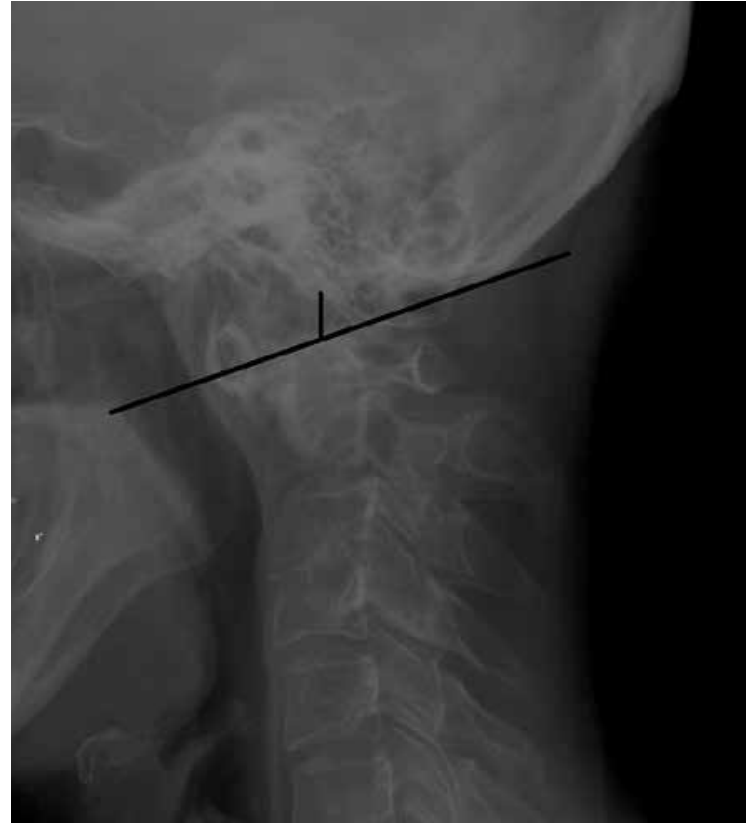

Figure 8. Lateral radiograph of 62 y.o. female diagnosed with RA showing anterior AAS and basilar settling ( $8.5 \mathrm{~mm}$ by McGregor's method - black lines)

apparent diffusion coefficient (ADC) in MRI was helpful in identifying cervical cord abnormalities in patients with anterior AAS but no spinal abnormalities on standard T1- or T2-weighted sequences. Patients with anterior AAS had higher ADC in the spinal cord at the $\mathrm{C} 1$ level, which presumable suggests early biochemical disturbances of the spinal cord [37].

Anterior AAS is diagnosed on radiographs but may not be confirmed on MRI due to the neutral position of the patient. However, subaxial myelopathy is confirmed by MRI and may be suspected on routine radiography when spinous process erosions, axial shortening of vertebrae,

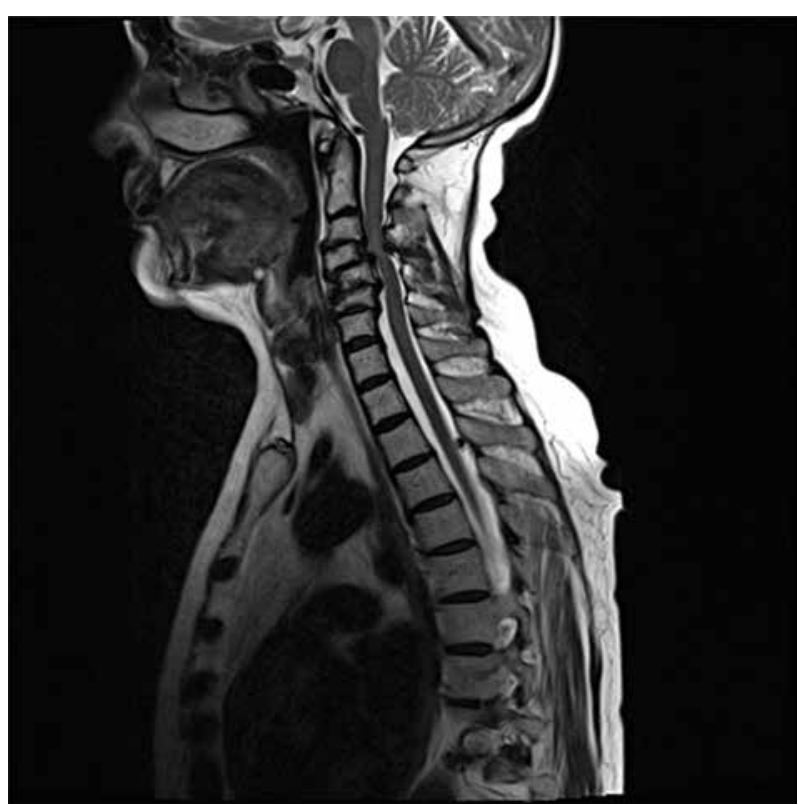

Figure 9. Sagittal MRI, T2-weighted sequence of 66 y.o. female diagnosed with RA showing multiple SAS at C3-C6 level 


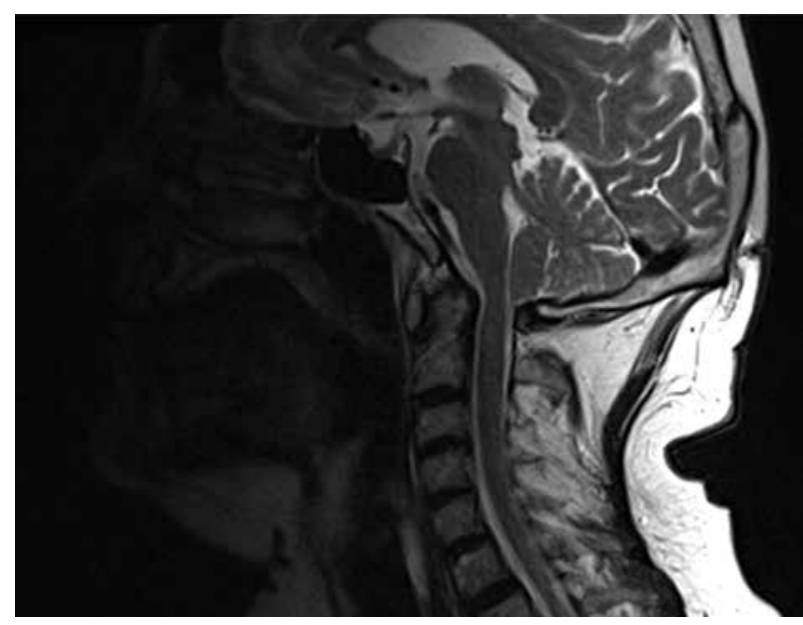

Figure 10. Sagittal MRI, T1-weighted sequence of 68 y.o. male diagnosed with RA showing dens erosions

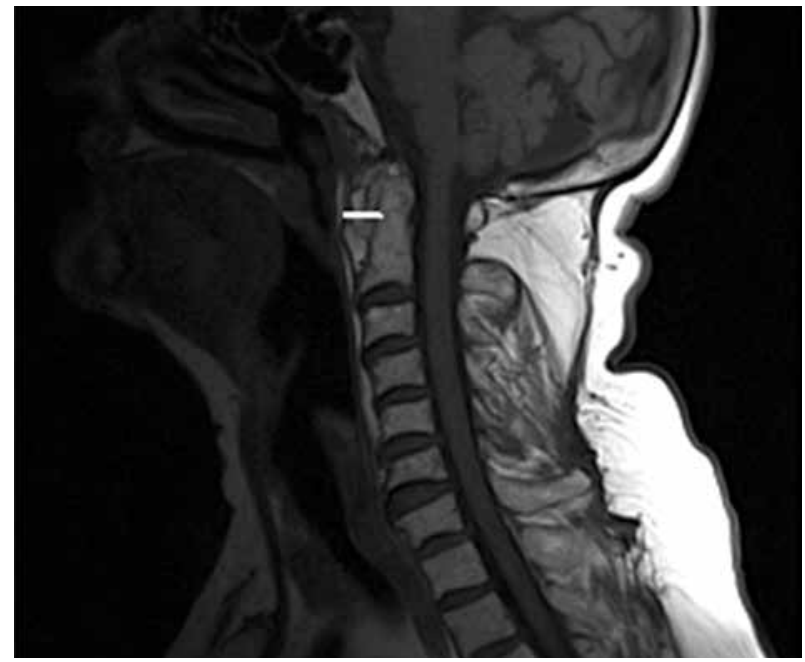

Figure 12. Sagittal MRI, T1-weighted sequence of 76 y.o. female diagnosed with RA showing extensive pannus formation and anterior AAS (4 mm; white line)

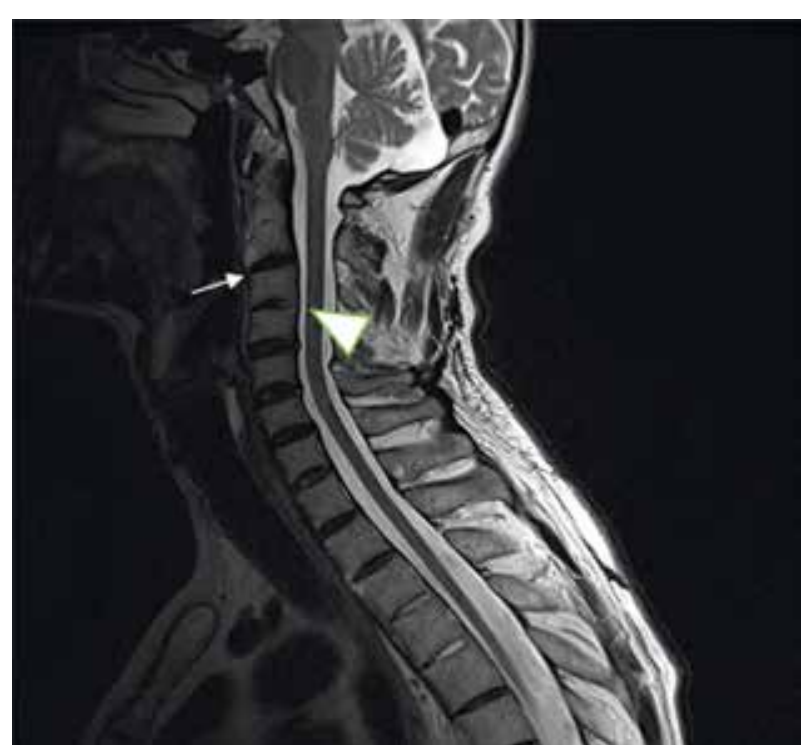

Figure 14. Sagittal MRI, T2-weighted sequence of 52 y.o. male diagnosed with ankylosing spondylitis showing subtle syndesmophytes at $\mathrm{C} 2 / \mathrm{C} 3$ (white arrow) level and posterior ankylosis of vertebral body at C $3 / C 4$ level (white arrowhead)

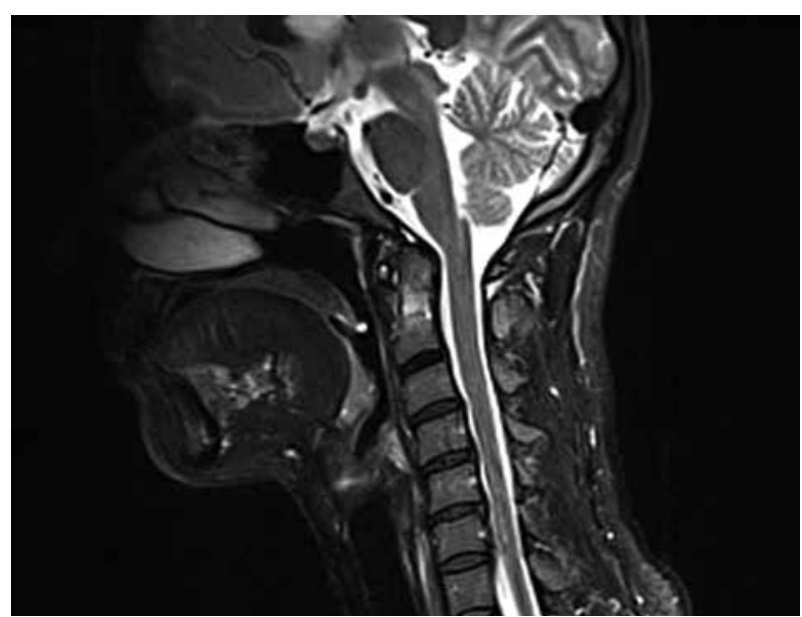

Figure 11. Sagittal MRI, TIRM T2-weighted image of 40 y.o. female diagnosed with RA showing dens bone marrow oedema and paradonoid efussion

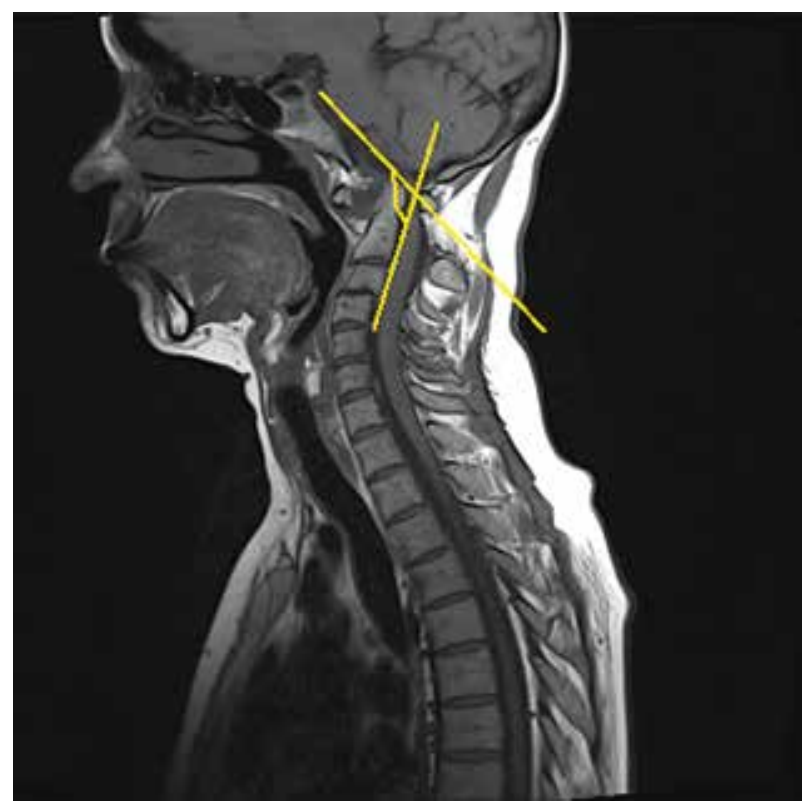

Figure 13. Sagittal MRI, T2-weighted sequence of 44 y.o. female diagnosed with RA showing vertical and posterior subluxation (PADI $<14 \mathrm{~mm}$ ) and cervicomedullary angle below $135^{\circ}$ (yellow lines), which indicates brainstem compression

and spinal canal narrowing are present. Deterioration of subaxial myelopathy may be associated with the degree of anterior slippage, vertebrae or intervertebral space collapse, or destruction of the spinous process or apophyseal joint. Furthermore, younger patients and those with a longer disease duration, use of steroids, and a severe course of RA are at higher risk for subaxial myelopathy [38].

During clinical evaluation, Ranawat's neurological scale has been associated with altered signals of the spinal cord on MRI [39]. Zhang et al. conducted a meta-analysis to study the prevalence of cervical spine involvement in the last 54 years (1960-2014). They found a decrease in the prevalence of anterior AAS but no changes in basilar settling or SAS. Thus, the progressive nature of C-spine involvement remains an issue [40]. 


\section{Ankylosing spondylitis}

Radiological involvement is present in up to $54 \%$ of AS cases and increases with age and disease duration [41]. Anterior AAS is present in up to $21 \%$ of cases, while vertical AAS is only found in $2 \%$, and it has been found to correlate with high levels of C-reactive protein (CRP), peripheral arthritis, the degree of sacroiliitis, uveitis, and the use of biological treatment [12,42]. Maas et al. [43] found that $52 \%$ of patients with AS had syndesmophytes, and $25 \%$ had ankylosis of the facet joints. Interestingly, in this study, $26 \%$ and $13 \%$ of patients who underwent biological treatment developed new syndesmophytes and facet joint ankylosis, respectively, within 4 years. Destruction of the facet joints was linked to a longer disease duration and the presence of uveitis, psoriasis, or inflammatory bowel diseases, as well as high disease activity, a high modified stroke ankylosing spondylitis spinal score (mSASSS), the presence of syndesmophytes, and an increased occiput-towall distance measured at clinical assessment (the Flesche test) [43]. The progression of facet joint damage was associated with the presence of facet joint destruction early in AS and an increased occiput-to-wall distance [43].

Ossification of the posterior longitudinal ligament is seen in $16 \%$ of cases and may lead to myelopathy [11]. Serious complications, including death, may result from vertebral fractures at the cervical level. They are associated with chin-to-chest deformity (evaluated during the clinical assessment) and are caused by excessive kyphosis. This type of fracture is the most common reason for surgical intervention at the level of the C-spine in AS [14]. Figure 14 presents syndesmophytes and ankylosis on MRI in a 52-year-old patient with a 24-year history of ankylosing spondylitis.

\section{Psoriatic arthritis}

Blau et al. categorized C-spine involvement in PsA into 2 heterogeneous groups: ankylosing and rheumatoid-like [44]. The first group is more commonly encountered and is characterized by the presence of ankylosis, syndesmophytes, and ligamental calcification. Rheumatoid-like PsA tends to be erosive with atlanto-axial subluxations [44, 45]. The C1/C2 level is affected in $30-75 \%$ of cases [44]. In a study conducted by Laiho et al., the most frequent lesion in the C-spine was bone ankylosis, accounting for $11 \%$ of patients, followed by anterior AAS in $8 \%$ of patients and vertical AAS in 5\%. In PsA, thick and irregular asymmetric syndesmophytes, called parasyndesmophytes, are typically found in the thoraco-lumbar spine [9] but do not occur in the C-spine [46]. Patients with the polyarticular subtype of PsA are at the greatest risk of developing cervical lesions [47]. In a previous study, the duration of psoriatic arthritis and the presence of radiocarpal erosions were prognostic factors for $\mathrm{C}$-spine disease, but no correlation was found regarding the severity of skin or nail disease [45].

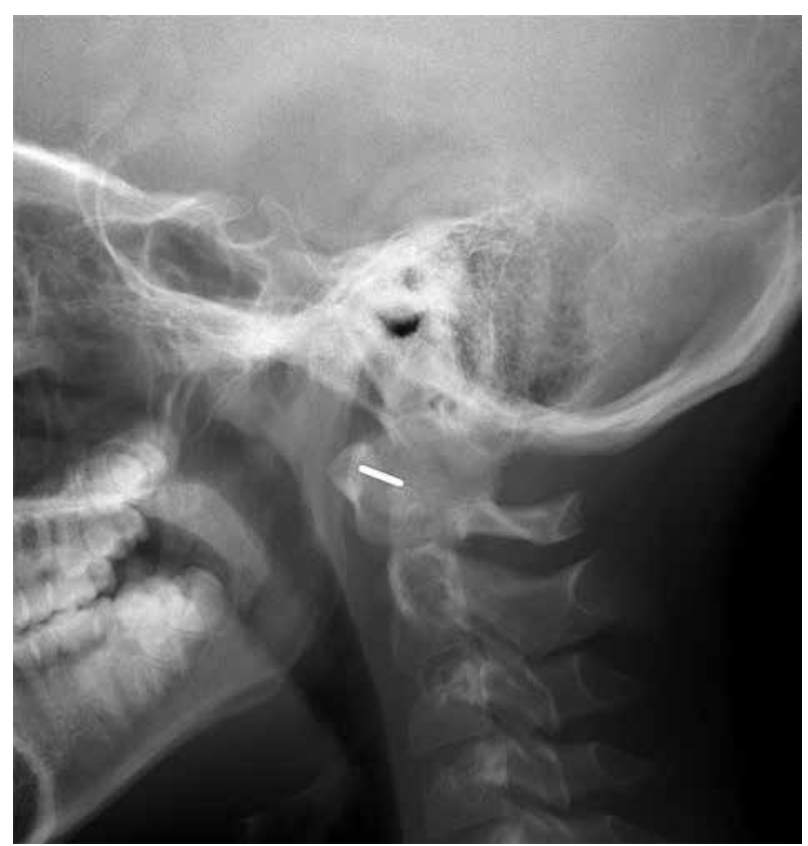

Figure 15. Lateral radiograph neutral position of 12 y.o. boy diagnosed with JIA showing anterior AAS ( $6 \mathrm{~mm}$; white line)

\section{Juvenile idiopathic arthritis}

The most characteristic lesions in JIA include apophyseal joint ankylosis and vertebral hypoplasia. Other less specific features include dens erosions, anterior AAS, SAS, and ligamental calcifications. Ankylosis of apophyseal joints is the most common lesion, observed in up to $41 \%$ of patients $[19,46]$. Fusion typically begins at the C2/C3 level, and patients with early-onset JIA are at increased risk. It is common among patients with the polyarticular subtype of JIA and juvenile ankylosing spondylitis but has a similar rate of occurrence in seronegative and seropositive patients [19]. Regarding subluxations, anterior AAS has been observed in up to $33 \%$ of patients with the rheumatoid factor (RF) antibody, predisposing them to severe anterior AAS (Figure 15). Dens erosions were seen in up to $19 \%$ of cases, while SAS was seen in up to $7 \%$ [16].

\section{Conclusions}

Classic radiography is the first-line modality for C-spine imaging in inflammatory arthritis. MRI and CT allow for a more precise diagnosis by providing a detailed assessment of anatomy and soft-tissue pathologies. C-spine involvement in RA patients has a unique presentation, and it can be clinically silent, subtle, or nonspecific in the initial stages of RA, which may lead to severe cervical spine injury and peripheral joint disease. Furthermore, very few studies have focused on patients with SpA and JIA. Among SpA, mainly AS and PsA may affect the C-spine and lead to instability. In SpA, syndesmophytes, parasyndesmophytes, and bone ankylosis are common radiological findings. In JIA, early ankylosis is the most serious 
complication. C-spine imaging in patients with JIA is particularly important because it is difficult to assess clinically. Radiography has low sensitivity in children because it provides morphological and structural information more typical of the later phases of inflammation, so early detection with MRI is of utmost importance for prompt therapeutic intervention. Moreover, the early introduction of anti-tumour necrosis factor alpha (anti-TNFa) medica- tion in the treatment of JIA patients with the severe form of the disease provides an opportunity to delay or prevent severe joint damage.

\section{Conflicts of interest}

The authors report no conflict of interest.

\section{References}

1. Sudoł-Szopińska I. Diagnostyka obrazowa zapalnych chorób reumatycznych. PZWL Wydawnictwo Lekarskie, Warszawa 2016.

2. Oláh C, Kardos Z, Kostyál L, et al. Assessment of cervical spine involvement in rheumatoid arthritis patients in the era of biologics: a real-life, cross-sectional MRI study. Rheumatol Int 2020; 40: 915-921.

3. Sudoł-Szopińska I, Kontny E, Maśliński W, et al. The pathogenesis of rheumatoid arthritis in radiological studies. Part I: Formation of inflammatory infiltrates within the synovial membrane. J Ultrason 2012; 12: 202-213.

4. Sudoł-Szopińska I, Kontny E, Maśliński W, et al. Significance of bone marrow edema in pathogenesis of rheumatoid arthritis. Pol J Radiol 2013; 78: 57-63.

5. Wasserman BR, Moskovich R, Razi AE Rheumatoid arthritis of the cervical spine - clinical considerations. Bull NYU Hosp Jt Dis 2011; 69: $136-148$

6. Iizuka H, Nishinome M, Sorimachi Y, et al. The characteristics of bony ankylosis of the facet joint of the upper cervical spine in rheumatoid arthritis patients. Eur Spine J 2009; 18: 1130-1134.

7. Rudwaleit M, van der Heijde D, Landewé R, et al. The development of Assessment of SpondyloArthritis international Society classification criteria for axial spondyloarthritis (part II): validation and final selection. Ann Rheum Dis 2009; 68: 777-783.

8. Braun J, Bollow M, Remlinger G, et al. Prevalence of spondylarthropathies in HLA-B27 positive and negative blood donors. Arthritis Rheum 1998; 41: 58-67.

9. Sudoł-Szopińska I, Matuszewska G, Kwiatkowska B, et al. Diagnostic imaging of psoriatic arthritis. Part I: etiopathogenesis, classifications and radiographic features. J Ultrason 2016; 16: 65-77.

10. Aufdermaur M. Pathogenesis of square bodies in ankylosing spondylitis. Ann Rheum Dis 1989; 48: 628-631.

11. Ramos-Remus C, Gomez-Vargas A, Guzman-Guzman JL, et al. Frequency of atlantoaxial subluxation and neurologic involvement in patients with ankylosing spondylitis. J Rheumatol 1995; 22: 2120-2125.

12. Tan S, Wang R, Ward MM. Syndesmophyte Growth in Ankylosing Spondylitis. Curr Opin Rheumatol 2015; 27: 326-332.

13. Koning A de, Schoones JW, Heijde D van der, et al. Pathophysiology of axial spondyloarthritis: Consensus and controversies. Eur J Clin Invest 2018; 48: e12913.

14. Lazennec JY, d’Astorg H, Rousseau MA. Cervical spine surgery in ankylosing spondylitis: Review and current concept. Orthop Traumatol Surg Res OTSR 2015; 101: 507-513.
15. Ravelli A, Martini A. Juvenile idiopathic arthritis. Lancet Lond Engl 2007; 369: 767-778

16. Elhai M, Wipff J, Bazeli R, et al. Radiological cervical spine involvement in young adults with polyarticular juvenile idiopathic arthritis. Rheumatol Oxf Engl 2013; 52: 267-275.

17. McGhee JL, Burks FN, Sheckels JL, et al. Identifying children with chronic arthritis based on chief complaints: absence of predictive value for musculoskeletal pain as an indicator of rheumatic disease in children. Pediatrics 2002; 110: 354-359.

18. Endén K, Laiho K, Kautiainen H, et al. Subaxial cervical vertebrae in patients with juvenile idiopathic arthritis - something special? Joint Bone Spine 2009; 76: 519-523.

19. Laiho K, Hannula S, Savolainen A, et al. Cervical spine in patients with juvenile chronic arthritis and amyloidosis. Clin Exp Rheumatol 2001; 19: 345-348.

20. Younes M, Belghali S, Kriâa S, et al. Compared imaging of the rheumatoid cervical spine: prevalence study and associated factors. Joint Bone Spine 2009; 76: 361-368.

21. Kauppi M, Neva MH Sensitivity of lateral view cervical spine radiographs taken in the neutral position in atlantoaxial subluxation in rheumatic diseases. Clin Rheumatol 1998; 17: 511-514.

22. Matar LD, Doyle AJ. Prevertebral soft-tissue measurements in cervical spine injury. Australas Radiol 1997; 41: 229-237.

23. Sudoł-Szopińska I, Jurik AG, Eshed I, et al. Recommendations of the ESSR Arthritis Subcommittee for the use of magnetic resonance imaging in musculoskeletal rheumatic diseases. Semin Musculoskelet Radiol 2015; 19: 396-411.

24. Bell GR, Stearns KL. Flexion-extension MRI of the upper rheumatoid cervical spine. Orthopedics 1991; 14: 969-973; discussion 973-974.

25. Riew KD, Hilibrand AS, Palumbo MA, et al. Diagnosing basilar invagination in the rheumatoid patient. The reliability of radiographic criteria. J Bone Joint Surg Am 2001; 83: 194-200.

26. Casey AT, Crockard HA, Geddes JF, et al. Vertical translocation: the enigma of the disappearing atlantodens interval in patients with myelopathy and rheumatoid arthritis. Part I. Clinical, radiological, and neuropathological features. J Neurosurg 1997; 87: 856-862.

27. White AA, Johnson RM, Panjabi MM, et al. Biomechanical analysis of clinical stability in the cervical spine. Clin Orthop 1975; 85-96.

28. Yurube T, Sumi M, Nishida K, et al. Incidence and aggravation of cervical spine instabilities in rheumatoid arthritis: a prospective minimum 5-year follow-up study of patients initially without cervical involvement. Spine 2012; 37: 2136-2144. 
29. Ulbrich EJ, Schraner C, Boesch C, et al. Normative MR cervical spinal canal dimensions. Radiology 2014; 271: 172-182.

30. Bundschuh C, Modic MT, Kearney F, et al. Rheumatoid arthritis of the cervical spine: surface-coil MR imaging. AJR Am J Roentgenol 1988; 151: 181-187.

31. Nguyen HV, Ludwig SC, Silber J, et al. Rheumatoid arthritis of the cervical spine. Spine J 2004; 4: 329-334.

32. Delamarter RB, Bohlman HH. Postmortem osseous and neuropathologic analysis of the rheumatoid cervical spine. Spine 1994; 19: $2267-$ 2274 .

33. Reijnierse M, Dijkmans BA, Hansen B, et al. Neurologic dysfunction in patients with rheumatoid arthritis of the cervical spine. Predictive value of clinical, radiographic and MR imaging parameters. Eur Radiol 2001; 11: 467-473.

34. Menezes AH, VanGilder JC, Clark CR, et al. Odontoid upward migration in rheumatoid arthritis. An analysis of 45 patients with "cranial settling". J Neurosurg 1985; 63: 500-509.

35. Gillick JL, Wainwright J, Das K. Rheumatoid arthritis and the cervical spine: a review on the role of surgery. Int J Rheumatol 2015; 2015 : 252456.

36. Collins DN, Barnes CL, FitzRandolph RL. Cervical spine instability in rheumatoid patients having total hip or knee arthroplasty. Clin Orthop Relat Res 1991; 272: 127-35.

37. Mańczak M, Pracoń G, Sudoł-Szopińska I, Gasik R. Apparent diffusion coefficient as an indicator of spinal cord compression due to anterior atlanto-axial subluxation in rheumatoid arthritis patients. Eur Spine J 2019; 28: 2352-2358.
38. Yonezawa T, Tsuji H, Matsui $\mathrm{H}$, et al. Subaxial lesions in rheumatoid arthritis. Radiographic factors suggestive of lower cervical myelopathy. Spine 1995; 20: 208-215.

39. Narváez JA, Narváez J, Serrallonga M, et al. Cervical spine involvement in rheumatoid arthritis: correlation between neurological manifestations and magnetic resonance imaging findings. Rheumatol Oxf Engl 2008; 47: 1814-1819.

40. Zhang T, Pope J. Cervical spine involvement in rheumatoid arthritis over time: results from a meta-analysis. Arthritis Res Ther 2015; 17: 148.

41. El Maghraoui A, Bensabbah R, Bahiri R, et al. Cervical spine involvement in ankylosing spondylitis. Clin Rheumatol 2003; 22: 94-98.

42. Lee JS, Lee S, Bang SY, et al. Prevalence and risk factors of anterior atlantoaxial subluxation in ankylosing spondylitis. J Rheumatol 2012; 39: 2321-2326.

43. Maas F, Spoorenberg A, Brouwer E, et al. Radiographic damage and progression of the cervical spine in ankylosing spondylitis patients treated with TNF- $\alpha$ inhibitors: facet joints vs. vertebral bodies. Semin Arthritis Rheum 2017; 46: 562-568.

44. Blau RH, Kaufman RL. Erosive and subluxing cervical spine disease in patients with psoriatic arthritis. J Rheumatol 1987; 14: 111-117.

45. Jenkinson T, Armas J, Evison G, et al. The cervical spine in psoriatic arthritis: a clinical and radiological study. Br J Rheumatol 1994; 33 : 255-259.

46. Laiho K, Kauppi M. The cervical spine in patients with psoriatic arthritis. Ann Rheum Dis 2002; 61: 650-652.

47. Sudoł-Szopińska I. Atlas RTG zapalnych chorób reumatycznych. PZWL Wydawnictwo Lekarskie, Warszawa 2019. 